\title{
Biotech remains unloved by the more informed
}

\section{The media may be providing the message — but is anyone heeding the call?}

Sir - Public hostility towards biotechnologies is frequently attributed to lack of information, due to poor and insufficient media coverage. For this reason, scientific researchers and policy-makers often call for journalists to give more attention to scientific issues, for better information campaigns and for more communication of science, to improve general understanding and thereby lead to greater public support for biotechnologies and other innovations. But is this approach correct?

In 2000 and 2001, with partial support from the Giannino Bassetti Foundation, we carried out two surveys of Italian public opinion. These were specifically to analyse the relationships between exposure to science in the media, information on biotechnologies, trust in science, and attitudes to biotechnologies. A representative sample of 1,022 Italian citizens aged over 18 were interviewed by phone in September 2000; another representative sample of 1,017 citizens were interviewed in November 2001. Some questions were identical for the two groups, others were year-specific. (A copy of the full list of questions used in the survey and the percentage response rates is available from M.B.)

Respondents were asked about their level of exposure to science in specified daily newspapers, television and radio science programmes, popular science books and magazines. We used questions similar to those of 1999 Eurobarometer (see http://europa.eu.int/comm/research/ pdf/eurobarometer-en.pdf), but also asked additional ones about trust in science and scientists, and the use, risks and moral acceptability of biotechnologies.

Our results confirm previous suspicions that exposure to information does not always lead to greater trust in biotechnologies. We also find that greater exposure to science in the media does not necessarily mean a higher level of understanding. The proportion of subjects who think "only genetically modified tomatoes contain genes while ordinary tomatoes don't", for example, is almost identical among those with high (29\%) and low (31\%) exposure to science in the media. More than a quarter of the 'regular' consumers of science in the media (28\%) cannot give more than one correct answer to five questions about biotechnologies, and more than half (57\%) cannot give more than two correct answers.

High exposure to science in the media does not significantly reduce opposition to applications such as "taking genes from plant species and transferring them into crop plants, to make them more resistant to insect pests" or "introducing human genes into animals to produce organs for human transplants, such as into pigs for human heart transplants". But it does result in greater criticism for some applications: $64 \%$ of the most exposed subjects consider embryo research to be ethically unacceptable compared with 59\% of the less exposed, and $80 \%$ of regular consumers of science in the media consider reproductive cloning useless compared with $76 \%$ of low consumers.

Of course, media exposure to science does not guarantee accurate information; indeed, there are frequent complaints about the quality of science coverage by the mass media. People who are exposed to at least one high-quality source of public communication of science (for example, the Italian edition of Scientific American) are more likely to have a positive attitude to biotechnologies. Yet this result merely highlights a well-known paradox in the communication of science: the greatest impact is on a small minority, who are most likely to have the information already.

A high level of information does not guarantee a positive attitude: $49 \%$ of the better-informed respondents think that transferring genes into fruit or vegetables is useless, and 54\% think it is risky. Embryo research fares poorly $(60 \%$ in both groups consider it unacceptable), whereas cloning for reproductive purposes is even more severely judged by the better informed than by the less well informed.

A higher level of information is associated with the desire for stricter state regulation of biotechnologies, as well as with the belief that regulation should not be left either to companies or to scientists alone. The better informed are also more likely to trust consumers' organizations and scientific institutions more than potential beneficiaries (such as patients' groups) and, sometimes, government institutions.

If media exposure to science does not account for different attitudes to biotechnologies, what does? Attitudes appear to be rooted at a deeper, cultural level where values (such as trust and conception of risk) are heavily involved and media information does not reach. Public awareness of biotechnologies is increasing and the level of education seems to be more important than other factors in explaining attitudes in this area. So it may be wise to recommend that at least as much attention is devoted to science education - both in terms of research and of programmes and investments - as to the mass-media communication of science.

Massimiano Bucchi ${ }^{\star}$, Federico Neresini $\dagger$

${ }^{\star}$ Department of Social Sciences, University of

Trento, via Verdi 26 - 38100, Trento, Italy

e-mail:mbucchi@soc.unitn.it

†Department of Sociology, University of Padova, via S. Canziano 8, 35122 Padova, Italy

\section{Nothing automatic about ion-channel structures}

Sir-My colleagues and I were shocked to read your News report "Protein chemists favour automatic answers" (ref. 1) in which the chloride ion channel was featured prominently as an example of an important protein structure determined with the help of highthroughput techniques. In the report, Neil Isaacs of Glasgow University is quoted as saying that the chloride ion-channel structure "could not have been done without automation".

In fact, we used no automation or high-throughput methods to solve the chloride-channel structure ${ }^{2}$. Indeed, high-throughput methods have played no part in any of the difficult ion-channel structure determinations completed in my laboratory ${ }^{3-5}$. Our success has rested solely

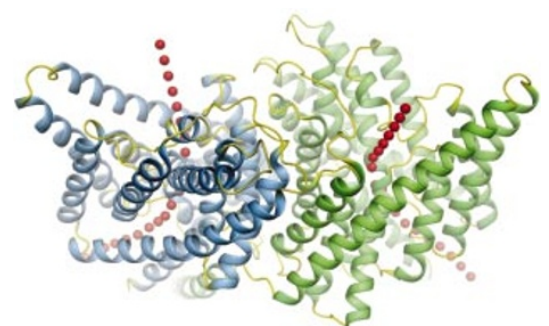

Chloride ion channel: structure solved by traditional science.

on the intense focus, hard work and thoughtful approach of a small group of scientists intent on solving an important problem in biological chemistry.

I do not wish to join the debate over the wisdom of funding robotic structural biology in the United Kingdom. I do, however, wish to set the record straight concerning a misrepresentation of the science carried out in my own laboratory. The explanation for why we have made 
good progress is simple - we try hard to understand the proteins that we work with. We study the structure and function of ion channels in one small laboratory. I do not have a 'structure group' and a 'function group'; young scientists who come to work with me pursue the structural and functional sides of their projects as a single endeavour. If you want to solve the structure of an ion channel it helps to understand ion channels. To understand ion channels you must study their function. Our approach is not profound, it is traditional hypothesis-driven science, and it works.

\section{Roderick MacKinnon}

Howard Hughes Medical Institute, Rockefeller University, 1230 York Avenue, New York, New York 10021, USA

\footnotetext{
1. Adam, D. Nature 415, 822 (2002)

2. Dutzler, R., Campbell, E. B., Cadene, M., Chait, B. T. \& MacKinnon, R. Nature 415, 287-294 (2002).

3. Doyle, D. A. et al. Science 280, 69-77 (1998).

4. Morais-Cabral, J. H., Zhou, Y. \& MacKinnon, R. Nature 414, 37-42 (2001).

5. Zhou, Y., Morais-Cabral, J. H., Kaufman, A. \& MacKinnon, R. Nature 414, 43-48 (2001).
}

\section{Opportunities for women in science (Russia, 1912)}

Sir - Caroline Herzenberg (Nature $414,843 ; 2001)$ is correct to suggest in Correspondence that the two women in the photograph of Ivan Petrovich Pavlov and his group are Maria Kapitonovna Petrova and Maria Nikolaevna Erofeeva (alternatively spelt "Nikolayevna Yerofeyeva"). The original, taken in Pavlov's Department of Physiology at the Military Medical Academy in 1912, includes Pavlov, seventeen male co-workers and the two female co-workers.

Erofeeva and Petrova were members of the first generation of women to enter Pavlov's laboratory, capitalizing on the expanded opportunities for women in the wake of the 1905 revolution. Erofeeva performed important experiments in 1910-12 that supported Pavlov's view that any environmental agent could, in principle, become a conditional stimulus. She defended her doctoral thesis in 1912 and, unlike most of Pavlov's co-workers, continued to work in his laboratory until taking a position at the Petropavlovsk Hospital and the P. F. Lesgaft scientific institute, where she continued her research until her death in 1925.

Petrova completed her doctoral thesis, on the nature and interaction of excitation and inhibition, in 1914. She and Pavlov became lovers that same year, Petrova becoming Pavlov's most important co-worker from about 1921 until his death in 1936. She created and was the principal force behind the laboratory's increasingly important line of investigation into "the experimental pathology and therapeutics of higher nervous activity". She directed the department of physiology and pathophysiology of higher nervous activity at the Leningrad Institute for the Improvement of Physicians from 1935 to 1941, and was also a prolific researcher and laboratory director at the Physiological Institute of the USSR Academy of Sciences. She survived the siege of Leningrad, won a Stalin prize for scientific research in 1946, and died in 1948.

Pavlov himself conducted very few of the experiments underlying his Nobel Prize-winning research on digestion and his more famous investigations on conditional reflexes, so his co-workers were central to his laboratory's research a subject I have previously covered in Pavlov's Physiology Factory: Experiment, Interpretation, Laboratory Enterprise (Johns Hopkins University Press, Baltimore and London, 2002). I hope to rescue Erofeeva, Petrova and other equally interesting co-workers of the later period from obscurity in my forthcoming biography of Pavlov.

\section{Daniel P. Todes}

Department of History of Science, Medicine and Technology, The Johns Hopkins University, 1900 East Monument Street, Baltimore, Maryland 21205, USA

\section{Job-seekers, be careful of what you're signing}

Sir - My colleagues and I now strongly advise all our undergraduate and graduate students planning to enter industry to "read the fine print" specifically, any exclusion clauses. It pays to check out this apparently small but possibly very significant detail before firmly accepting an offer, certainly before signing a contract or relocating. We feel that this precaution is valuable to any professional considering a change of employer, in addition to the familiar considerations of job satisfaction (of prime importance); type of work; size, type and health of company; location; and company benefits.

Some companies ask new employees to sign an agreement covering issues of patent ownership and confidentiality, for example agreeing that the company is the owner of any technical idea developed by the employee; or that the employee must not disclose or use outside the company any information that is proprietary to the company, either while an employee or afterwards. Such agreements, which must be signed upon starting a new job, are commonplace to cover the legitimate right of the company to protect its proprietary ideas and technology.

But some companies attempt to impose other, considerably more demanding, requirements. One might be that a new employee agrees, for a stipulated time after taking employment with a different company, not to work in areas of research or technology in which he or she had been directly involved while working for the present company. A more extreme requirement is that the employee is not allowed to work or consult for a competitor for a stated period of time after leaving the company, sometimes for as long as two years.

Typically, of course, a person accepting a position with a new company has no thought of working elsewhere. But who can count on anything lasting forever? The level of job satisfaction could change over time; the employee may wish to move; the work environment might become degraded through economies or ineffective management; staff could be laid off, as happens often in industry these days; or the employee might simply find a new opportunity with another company. Such reasons for change can arise relatively early in a person's career or after many years.

When embarking on a possible career move, the employee may have forgotten signing the agreement, but the company management will remember, and will remind the employee of the binding nature and implications of agreements that operate beyond the term of employment with the new employer.

So, our core advice to our students is that — before they make their final decision among different job offers, and before they have left their university town or home town - they ask any company offering them a job to send them copies of all agreements that they will be asked to sign when they join the organization. They can then seek legal advice in case of troubling 'non-compete' clauses. The requirements written into confidentiality agreements range widely from the quite mild and reasonably undemanding to those that go beyond the bounds of what I personally think ethically justifiable and proper.

Whatever the specifics, all these agreements are written in the interest of giving the company the protection that it feels it needs, and not for the benefit of the individual employee.

\section{Ken Larner}

Department of Geophysics, Colorado School of

Mines, Golden, Colorado 80401, USA 